\title{
¡El español era tan fácil y ahora se ha vuelto tan difícil! Un estudio sobre las motivaciones de profesores de ELE en formación y egresados para la elección de Letras con Español
}

\author{
Nair Floresta Andrade Neta \\ Universidade Estadual de Santa Cruz (UESC)
}

\begin{abstract}
Resumo
Há alguns anos, publicamos um artigo titulado Aprender español es fácil porque hablo portugués: Ventajas y desventajas de los brasileños para aprender español que, segundo os dados que temos, tem sido de grande interesse para professores e aprendizes de Espanhol como Língua Estrangeira dentro e fora do Brasil. No presente artigo, retomamos a discussão acerca da facilidade desde outro enquadramento teóricometodológico, como uma das motivações para a opção pelo Espanhol como Língua Estrangeira e como segunda habilitação no curso de Letras. Entre os aspectos que serão tratados, se encontra a relação entre a facilidade e um fenômeno afetivo que denominamos de gostatividade. Os dados provêm de uma pesquisa em educação, de corte qualitativo, centrada na percepção de 66 sujeitos participantes, vinculados ao curso de Letras de uma universidade pública baiana, cenário do estudo. Como procedimento de análise, utilizamos um modelo simplificado da Análise de Conteúdo.
\end{abstract}

Palavras-chave: formação de professor; Letras; ELE; facilidade; gostatividade.

\section{Resumen}

Hace algunos años, publicamos un artículo titulado Aprender español es fácil porque hablo portugués: Ventajas y desventajas de los brasileños para aprender español que, según los datos que tenemos, ha sido y sigue siendo de gran interés para profesores y aprendices de Español como Lengua Extranjera dentro y fuera de Brasil. En el presente artículo, retomamos la discusión acerca de la facilidad, desde otro marco teórico-metodológico, como una de las motivaciones de la opción del Español como Lengua Extranjera y segunda habilitación en la carrera de Letras. Entre los aspectos que serán tratados, se encuentra la relación entre la facilidad y un fenómeno afectivo al que hemos denominado gustatividad. Los datos provienen de una investigación educativa, de corte cualitativo, enfocada y centrada en la percepción de 66 sujetos participantes, vinculados a la carrera de Letras de una universidad pública bahiana, escenario del estudio. Como procedimiento de análisis, utilizamos un modelo simplificado del Análisis de Contenido.

Palabras clave: formación de profesor; Letras; ELE; facilidad; gustatividad. 


\begin{abstract}
A few years ago, we published an article entitled 'Learning Spanish is easy because I speak Portuguese: advantages and disadvantages of Brazilian people for learning Spanish'. According to the available data, this article has been of great interest to teachers and learners of Spanish as a foreign language in Brazil and abroad. In the present paper, we resume the discussion about this facility of learning Spanish, from another theoretical and methodological framework, and we examine it as one of the motivations for the choice of Spanish as a foreign language and as a second major area of study in the Letters course. Among the issues to be addressed is the relationship between the learning facility and a phenomenon we call affective gustatividad. The data comes from a qualitative survey in education, focusing on the perceptions of 66 participating subjects, who are students in the Letters course at a public university in Bahia, which was the scene of the study. The analytical procedure used a simplified model of Content Analysis.
\end{abstract}

Keywords: teacher training; Letters course, ELE; facility; gustatividad

\title{
INTRODUCCIÓN
}

Para lograr nuestro objetivo central, que es tratar de la facilidad como una de las motivaciones para la elección del Español como Lengua Extranjera (en adelante, ELE) y segunda habilitación en la carrera de Letras, seguiremos una línea de raciocinio más bien deductiva, o sea, trataremos, primeramente, de las motivaciones que guían a los participantes en la elección de la carrera y de la lengua extranjera en general; después, hablaremos de la gustatividad como un fenómeno afectivo, tal y como la vemos, para, finalmente, abordar el fenómeno más específico de la facilidad.

Para llegar a ello, además de esa introducción y de las consideraciones finales, hemos estructurado el artículo en dos partes: en la primera, nos referimos a los antecedentes y orígenes de los datos para que el lector se ubique y sepa desde qué lugar, teórico y empírico, estamos hablando. En la segunda parte, presentamos y discutimos los (y sobre los) datos.

Para fundamentar empíricamente la discusión, hemos utilizado algunas muestras del corpus de la investigación de la que trataremos en la primera parte, en forma de declaraciones de los sujetos, que aparecen enumeradas secuencialmente y con las indicaciones referentes a la categoría del sujeto informante (PEF equivale a profesor de Español en formación; PEE, a profesor de Español egresado y PEFP se refiere a profesor de Español formador de profesores) y a la técnica de investigación empleada 
para la obtención de los datos (EFG, equivale a entrevista focalizada de grupo y EI equivale a entrevista individual). Para darles más centralidad dentro de nuestro discurso, hemos utilizado el patrón de citas largas para las declaraciones, independientemente de su extensión. Todos los sujetos de las dos primeras categorías han recibido un nombre ficticio, mientras que los de la tercera categoría han sido denominados con la letra "P" (de Profesor formador) seguida de la numeración que le corresponde como informante $(1,2,3,4)$.

\section{ANTECEDENTES Y ORÍGENES DE LOS DATOS}

Hace unos años publicamos un artículo titulado Aprender español es fácil porque hablo portugués: Ventajas y desventajas de los brasileños para aprender español (Andrade Neta, 2000) que, a juzgar por la profusión con que es consultado, indicado y citado dentro y fuera de Brasil, ha sido de gran interés para profesores y aprendices de ELE. En aquella ocasión, aunque tratamos de la proximidad interlingüística entre el portugués (como lengua materna) y el español (como lengua extranjera) como un factor positivo, por facilitar y agilizar el aprendizaje del español, sobre todo en las etapas iniciales, también demostramos que esa misma proximidad podría considerarse una desventaja, al ser una fuente generadora de interferencias negativas. Tras una atenta lectura de los aspectos fonético-fonológicos, morfosintácticos y léxico-semánticos tratados en el referido artículo, el lector llega a la inevitable conclusión de que aprender español no es tan fácil para los lusohablantes brasileños como se supone.

En el presente artículo, ampliaremos un poco más la discusión en torno a la afirmación según la cual aprender español es fácil, pero, en esta ocasión, lo haremos desde un marco teórico-metodológico distinto. La situaremos como siendo una de las motivaciones para la elección de la carrera de Letras con Español, pero nuestro principal objetivo es presentar la otra cara de esa creencia, que encontramos en nuestra investigación doctoral cuando buscábamos evaluar cómo los participantes percibían la influencia de las emociones y sentimientos en la formación inicial de profesores de ELE 
(Andrade Neta, 2011) ${ }^{1}$. Se trata, más específicamente, de la relación de retroalimentación que ellos establecieron entre facilidad y gustatividad -un fenómeno afectivo que emergió de los datos, mencionado por los participantes para referirse a sus experiencias de "gusto", “afinidad" e "identificación" hacia la lengua extranjera, la carrera, la docencia, etc.

Los datos que serán presentados y discutidos en este artículo provienen del estudio que dio origen a nuestra tesis doctoral, anteriormente citada. Se trata de una investigación educativa, de corte cualitativo, llevada a cabo en carácter de cuasiparticipación, enfocada y centrada en la percepción de los 66 sujetos participantes, subdivididos en tres categorías de informantes: profesores de Español en formación (PEF), profesores de Español egresados (PEE) y profesores de Español formadores de profesores (PEFP), seleccionados mediante la técnica de muestreo por accesibilidad (Sabariego, 2004). El criterio básico de participación era el de estar vinculado al escenario de la investigación -una universidad pública brasileña- en la condición de alumno(a), alumno(a) egresado(a) o profesor(a) de Español de la carrera de Letras. Los datos fueron recogidos in situ mediante la utilización de tres técnicas cualitativas: la observación cuasi participativa (OCP), la entrevista focalizada de grupo (EFG) y la entrevista individual (EI), ambas semi-estructuradas. Para el análisis, utilizamos un modelo simplificado del Análisis de Contenido (Guerra, 2008). La representatividad y la generalización de los datos fueron garantizadas mediante la aplicación de los principios de diversidad y saturación (Guerra, 2008; Sabariego \& Bisquerra, 2004). Las categorías de análisis fueron definidas según el modelo abierto, o sea, no se definieron previamente sino que emergieron de los datos (Nascimento, 2002) y se constituyeron mediante la aplicación del criterio de categorización temática (Taylor \& Bogdan, 1987).

La temática que abordaremos en este texto fue discutida dentro de la subcategoría denominada "la motivación para la elección de Letras-ELE: carrera y habilitación”, que recoge las motivaciones de los participantes de cara a la elección tanto de la carrera de Letras-Español como de la lengua española como habilitación. Nuestra intención inicial era entender cómo, desde la percepción de los sujetos, la afectividad había influido en la elección de la carrera y de la lengua/habilitación. A continuación, presentaremos los resultados, partiendo de lo general (las motivaciones)

\footnotetext{
${ }^{1}$ Tesis doctoral dirigida por los profesores doctores D. Emilio García García (UCM-España) y Dña Marcia Paraquett (UFBA-Brasil) en el programa de Doctorado en Didáctica de las Lenguas y la Literatura, en la Facultad de Educación de la Universidad Complutense de Madrid.
} 
para lo particular (facilidad como factor de motivación para la elección de la carrera de Letras con Español y su relación con el fenómeno afectivo al que, en la tesis, hemos conceptualizado, definido y denominado con el término de gustatividad).

\section{DISCUSIÓN SOBRE LOS DATOS}

\section{La difícil tarea de elegir una carrera: motivaciones para la elección de Letras}

Cuando nos detuvimos en el análisis de las temáticas tratadas por los participantes de nuestra investigación doctoral, observamos que sus declaraciones contaban auténticas historias de relaciones afectivas, algunas de odio, otras de amor, marcadas por rupturas y confirmaciones, altibajos y vaivenes. Por analogía, afirmamos que elegir una carrera académica equivale a casarse con una profesión a la cual se debe querer para que la relación sea armónica y pueda aportar beneficios personales y sociales.

Según el neurocientífico Antonio Damasio (2007), optar por una carrera dista mucho de ser una decisión simple, puesto que conlleva un elevado grado de incertidumbre y complejidad al encontrarse en el ámbito de los dominios personal y social inmediato, para el cual no hay cálculos o previsiones precisas sobre el resultado al que posiblemente una determinada opción conduciría. Es por esto que, Bechara (2003), investigador del equipo de Damasio, sostiene que la única forma de que esta tarea decisoria se corone con éxito es seguir los "instintos" y los "sentimientos viscerales". Ese mecanismo, que ellos denominaron teóricamente de hipótesis del marcador somático, nos ayuda a entender la influencia de la afectividad -en sus diversas manifestaciones y, en especial, de las emociones- en la elección de la carrera y, posteriormente, en la confirmación (o no) de esa opción inicial. De acuerdo con la teoría damasiana,

[L]os marcadores somáticos son un caso especial de sentimientos generados a partir de emociones secundarias [o sociales]. Estas emociones y sentimientos han sido conectados, mediante aprendizaje, a resultados futuros predecibles de determinados supuestos. Cuando un marcador somático negativo se yuxtapone a un determinado resultado futuro, la combinación funciona como un timbre de alarma. En cambio, cuando lo que se superpone es un marcador somático positivo, se convierte en una guía de incentivo. (Damasio, 2007, p. 205)

Conforme a esa teoría, la construcción de los marcadores somáticos en el cerebro se da a lo largo de nuestro proceso de educación y socialización, especialmente 
durante la infancia y la adolescencia, que es cuando se generan las conexiones entre ciertos tipos de estímulo y determinados estados somáticos. Sin embargo, la acumulación progresiva de esa clase de conexiones sigue su curso, como un proceso de aprendizaje continuo e incesante. El fragmento que transcribimos a continuación amplía la comprensión del marcaje somático:

\begin{abstract}
Los marcadores somáticos se adquieren con la experiencia, bajo el control de un sistema de preferencias interno y bajo la influencia de una serie de circunstancias externas que incluyen no sólo entidades y acontecimientos con los que el organismo ha de interactuar, sino también convenciones sociales y normas éticas [...] El sistema de preferencia interno está sesgado o predispuesto de forma innata para evitar el dolor, buscar el placer potencial y, probablemente, está sesgado para conseguir estos fines en situaciones sociales. (Damasio, 2007, p. 211)
\end{abstract}

La posibilidad de que nuestras decisiones, en especial las de mayor complejidad, sufran la influencia encubierta de las emociones pone en entredicho la afirmación que hacen algunos de nuestros entrevistados de que optaron por la carrera de Letras, o por la lengua española como habilitación, por accidente. Por poner un ejemplo, veamos el caso de una alumna (Imma) del sexto semestre que participó en nuestra investigación en la categoría PEF, en las tres técnicas de recogida. Desde la percepción consciente de Imma, su opción por Letras fue accidental y casual, conforme expresan sus propias palabras:

(1) En realidad, nunca pretendí ser profesora, entré en Letras así, 'de paracaídas"” (Andrade Neta, 2011, p. 254).

Sin embargo, al analizar otro momento de su participación en la misma entrevista focalizada de grupo, encontramos indicios de la influencia de las emociones en su decisión aparentemente casual, que podría explicarse mediante el marcaje somático de la teoría damasiana. Al calor de las discusiones acerca de la influencia de la afectividad en la formación docente, Imma afirma lo siguiente, aproximadamente una hora después de la declaración anterior:

(2) Creo que las cosas que se hacen con amor, cuajan. Si el profesor ama la profesión, si imparte una asignatura que le gusta enseñar, si tiene placer en enseñar, sus alumnos lo sentirán [...] Lo digo por experiencia propia, elegí Letras por haber estudiado con un profesora [...] y estoy optando por el español [como futuro ámbito de actuación docente] por causa de algunos profesores de aquí. (Andrade Neta, 2011, p. 254) 
Al principio de la entrevista Imma creía en lo accidental de su elección, pero, a medida que sus recuerdos del período de escolarización iban aflorando evocaban la combinación entre amor, gustatividad y placer de enseñar, algo que ella percibía en una de sus profesoras y que, al marcarle emocionalmente de forma tan intensa, parece haber ejercido una fuerte influencia (encubierta) sobre su elección por Letras.

Aunque no lo parezca y no seamos tan conscientes de ello,

La elección de una carrera, con la consecuente opción por el ejercicio futuro de la profesión a esta vinculada, es una decisión de gran envergadura en la vida de una persona [...]. En el caso específico de la docencia, esta opción puede ser motivada por distintos factores: la facilidad y rapidez de inserción en el mercado laboral, las posibilidades reales de ingresar en la universidad, la disponibilidad de recursos y tiempo para estudiar una carrera, la influencia familiar, la admiración por un (los) maestro (s) durante la infancia o la adolescencia, la vocación, el deseo de mejorar la sociedad, etc. (Andrade Neta, 2011, p. 238)

Por lo que hemos podido observar en las declaraciones de nuestros participantes, una parte considerable de esos factores influyen en la decisión por la carrera de Letras al margen de la conciencia, probablemente, señalando ventajas y desventajas que, en algunos casos, ellos no llegan a percibir con claridad y seguridad.

Además de ser una decisión de gran envergadura -o quizás por ello-, elegir una carrera es, valga la repetición, una tarea sumamente compleja, por eso es natural encontrar tanta diversidad en el grado de conciencia de los motivos que impulsaron a nuestros participantes a optar por Letras, tal y como se puede apreciar en los fragmentos de las declaraciones que exponemos a continuación. Mientras que para Almudena (ejemplo 3), Beatriz (ejemplo 4) y Genoveva (ejemplo 5) la elección por Letras fue motivada por su gustatividad hacia la literatura, la lengua española y la lengua portuguesa, respectivamente, David (ejemplo 6) hizo esa elección sin tener mucha claridad con respecto a sus objetivos como profesor en formación (Andrade Neta, 2011, pp. 261-262).

(3) Cuando yo decidí hacer el Vestibular [para Letras] fue debido a la literatura, la disciplina que siempre me ha gustado. (Almudena, PEF-EFG1)

(4) Cuando hice el Vestibular para Letras, lo hice con la intención de ser profesora de español, amo el español. (Beatriz, PEF-EFG1)

(5) Cuando hice Letras, busqué ser profesora de portugués, la [materia] con la cual siempre tuve más afinidad. (Genoveva, PEF-EFG2)

(6) Yo entré en Letras sin ningún objetivo, no me gusta la lengua portuguesa, español era por afinidad [en términos de facilidad para aprobar en comparación con el 
inglés] y la literatura me daba igual. Entré porque tenía dos amigas que estudiaban Letras y me lo recomendaron. (David, PEF-EI)

En Brasil, la elección de una carrera de licenciatura en Letras implica, al menos, tomar tres decisiones subyacentes: la docencia como profesión; la escuela básica como ambiente de trabajo y la enseñanza de las lenguas (materna y/o extranjera) como área de actuación. Por si fuera poco, el proceso decisorio se vuelve aún más complejo si tenemos en cuenta que, en el escenario de nuestra investigación, Letras es una carrera polivalente, en la que confluyen tres áreas de formación docente: la enseñanza de lengua portuguesa como lengua materna, de español (o inglés) como lengua extranjera y sus literaturas y la enseñanza de literaturas de lengua portuguesa. Eso hace que la elección de la carrera se defina por el interés y la afinidad predominante por una de las tres áreas, que se suele construir previamente al ingreso en la universidad, pero se consolida o no, a lo largo de su duración.

$\mathrm{Al}$ analizar los datos referentes a los motivos de los participantes para la elección de la carrera, identificamos cuatro grupos: el primero estaba constituido por aquellos con motivaciones más generalistas o inespecíficas, que denominamos de interés inespecífico por Letras; en el segundo grupo fueron incluidos los que optaron por Letras atraídos por el interés por la lengua materna y/o sus literaturas (en adelante, LML); el tercer grupo estaba compuesto por los aspirantes interesados específicamente por la lengua española (ELE) y, finalmente, en el cuarto grupo reunimos a los que no informaron su motivación, o sea, o bien no contestaron a la pregunta correspondiente o bien dieron respuestas evasivas.

En términos cuantitativos, quedarían así representados gráficamente los grupos de participantes en función de las motivaciones para la elección de Letras: 


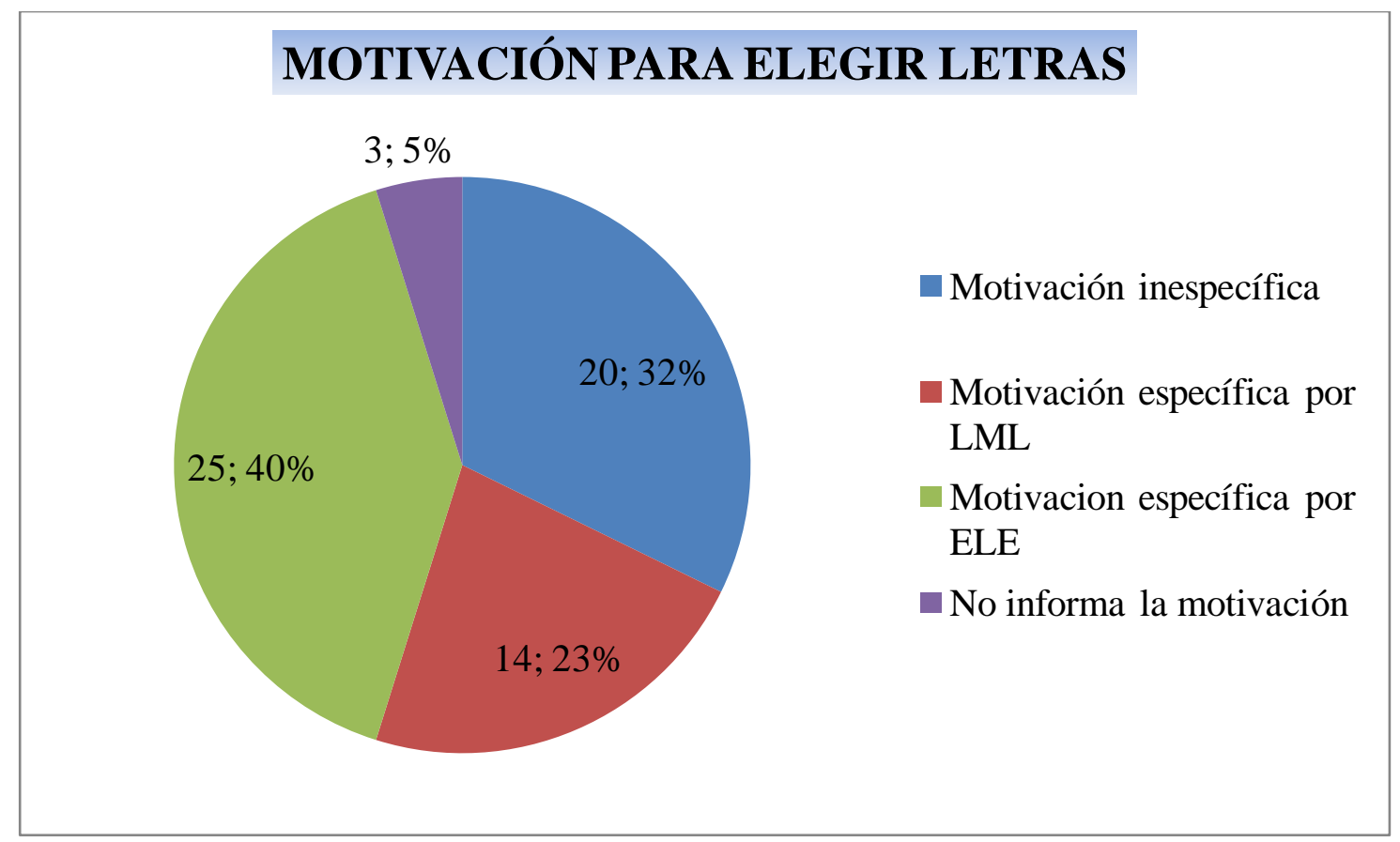

Gráfico 1: Motivación para elegir Letras -PEF y PEE (Andrade Neta, p. 261)

En el escenario de nuestra investigación hay una creencia muy arraigada, tanto por parte de los alumnos como de los profesores de Español, según la cual la elección del Español como Lengua Extranjera se debe a la facilidad para aprobar los procesos selectivos y que, una vez que han ingresado en la carrera, los aspirantes a Letras con español pasan a estudiar esa lengua extranjera por obligación, puesto que lo que realmente les interesaba era estudiar la habilitación de lengua portuguesa y/o sus respectivas literaturas. Las percepciones de Maricarmen e Imma, profesoras en formación, sintetizan muy bien esta idea. Según la percepción de aquella, "El 80\% de los [alumnos] que están aquí [en la universidad] están porque el español es fácil o porque es fácil aprobar [el Vestibular]". La percepción de Imma va en la misma dirección, pues cuando habla de la relación de sus compañeros de promoción con el Español, llega a la siguiente conclusión: "son pocos los que veo que realmente les gusta el español y buscan aprenderlo con ahínco. Los demás están aquí porque sí, porque no tienen otra alternativa, ya que la asignatura es obligatoria" (Andrade Neta, 2011, p. 262)

$\mathrm{Al}$ analizar las motivaciones de los participantes para ingresar en la carrera, constatamos, para nuestra sorpresa, que la creencia supra citada no se sostiene. En el gráfico 1, observamos que, al contrario de lo que creen profesores y alumnos de la institución locus, el número de aspirantes que ingresan en Letras motivados conscientemente por el ELE (40\%) es muy superior a los que lo hacen por interés en el 
estudio de la LML (el 23\%). Los que no han identificado claramente una inclinación por una de esas dos áreas (32\%) y los que no informaron sus motivaciones (5\%), vendrían a definirse a lo largo de la carrera.

Esos datos indican que cuando empieza un año académico en el contexto investigado, tendremos el siguiente panorama: (a) un grupo de alumnos que eligieron Letras atraídos por la lengua extranjera-ELE; (b) un segundo grupo interesado en la lengua materna y/o sus literaturas (LML) y (c) un tercer grupo que no sabe muy bien por qué ha elegido la carrera. Sobre este último diríamos -a modo de hipótesis a ser investigada con mayor profundidad - que las emociones les influyeron en la decisión de forma más encubierta. Cuando esa heterogeneidad de motivaciones, generadoras de una gran diversidad de expectativas, influye sobre la receptividad de los recién ingresados hacia los profesores y materias de la habilitación de menor interés, pueden producirse conflictos de intereses entre profesores y alumnos, convirtiéndose en una fuente adicional de malestar docente y discente.

\section{La facilidad como un desencadenante de la gustatividad}

Está muy extendida, en Brasil, la creencia de que para los lusohablantes brasileños aprender español es fácil. La facilidad presente en esta creencia suele ser tratada por profesores de ELE, en ejercicio y en formación, como un factor negativo en el ambiente educativo, ya que pone en desprestigio la lengua española en comparación con el inglés. Para Farías Fernández (1997), las semejanzas entre las dos lenguas en cuestión -que están en la base de la creencia en la facilidad- tienen como consecuencias: la desmotivación para estudiar ELE por inconsciencia acerca de la importancia de aprender esa lengua; la satisfacción con un nivel de subsistencia básico; la propensión a las interferencias, generalizaciones de reglas y ultracorrecciones; y la fosilización de los errores. En el mismo sentido, desde la percepción de Nuria, una participante de la investigación de la categoría PEF, la creencia en la facilidad da lugar a la falta de compromiso por parte del alumno y eso influye sobre la emocionalidad y la motivación del profesor:

(7) Percibo una falta de compromiso muy grande por parte de la mayoría de los alumnos. Con esa creencia de que el español es muy fácil, si es muy fácil, no tienen interés en aprenderlo. [Ante eso] me siento triste y, a veces, desmotivada. (Nuria, PEE-EFG2) (Andrade Neta, 2011, p. 260) 
De acuerdo con Andrade Neta (2011), para los licenciandos en Letras-Español (carrera de doble formación), la lengua española cumple tres papeles que pasan por un continuum de tres etapas: antes, durante y después de la carrera. Antes del ingreso en la universidad, la lengua es una materia más de la que se examinarán los aspirantes; una vez que hayan sido admitidos, el español se convierte en la segunda habilitación, compuesta por un conjunto de materias obligatorias del currículo de las que han de apropiarse durante la carrera, como hablante, investigador y profesor en formación. Finalmente, una vez que se hayan graduado, el ELE se legitima como una habilitación profesional que les autoriza oficialmente a ejercer la docencia en el área de ELE, en la educación básica, de las redes pública y privada, en el ámbito nacional.

Ese triple papel que la lengua desempeña en la vida de los estudiantes influirá tanto sobre sus motivaciones como sobre sus expectativas de ingreso. Hemos constatado que las experiencias previas con la lengua son el primer aliciente para la opción por ELE. Entre esas experiencias, destacamos: el primer contacto con la lengua en los cursos preparatorios ("cursinhos pre-vestibulares"); la facilidad con la que logran aprender los contenidos de los que se examinarán; la sensación de sentirse capaz de entender la letra de una canción o texto escrito en ese idioma; el contacto con la literatura y la cultura a través de canciones, novelas y telenovelas importadas de los países hispánicos y la afinidad con un profesor de ELE. Veamos algunos ejemplos de las percepciones de los sujetos de la investigación que dan una muestra de ello (Andrade Neta, 2011, p. 269)

(8) Mi primer contacto fue en el 'cursinho pre-vestibular' y de cara me enamoré de la lengua [...] El primer profesor que tuve fue un profesor uruguayo, entonces él hablaba la lengua, la usaba todo el tiempo y eso hizo que viviéramos la lengua, por eso me sentí seducida por el español. Cuando aprobé para Letras y entré en la universidad, me di cuenta de que aquí dentro la realidad es diferente (...) (Maríola, PEF-EFG2)

(9) Siempre he tenido curiosidad para aprender la lengua española desde el momento que pasé a conocer la cultura mejicana, incluso las propias telenovelas, siempre me gustaron. [...] Siempre he tenido ganas de aprender español. (Inés, PEF-EI)

(10) Aunque me gusta el inglés, [...] la lengua castellana me despierta más emoción. Quizá porque me trae recuerdos de la adolescencia. Fue en esta fase que me encanté por el español, porque el inglés ya me gustaba [...] La música fue la responsable de mi ingreso en este universo. (Lupe, PEE-EFG1)

Esta heterogeneidad de experiencias previas al ingreso en Letras van a determinar las expectativas, también heterogéneas, de los profesores en formación, no siempre atendidas en función de la naturaleza de la carrera, cuya finalidad es la 
formación inicial de profesores de ELE. A modo de ejemplo, veamos dos declaraciones relacionadas con esas expectativas:

(11) Siempre me ha gustado el español [...], entonces, lo elegí. No entré en la universidad con la intención de ser profesora, sino para estudiar el español. (Mariluz, PEF-EFG3)

(12) Siempre me ha parecido imprescindible aprender una lengua extranjera sabes, no sólo el español, como también el inglés, sabes, no necesariamente para ser profesora, sino para ser una buena traductora [...] (Bibiana, PEF-EFG 2)

(Andrade Neta, 2011, p. 262)

La confirmación o frustración de esas expectativas influirá, igualmente, en la disposición emocional de los alumnos $-\mathrm{y}$, en cierto modo, en la de los profesores formadores (véase en el ejemplo 16) - en y con respecto a las clases de ELE en la universidad, conforme podemos constatar en el siguiente bloque de declaraciones:

(13) No teníamos esa noción de que seríamos profesoras de Lengua Española, entramos en la carrera con la noción de que vamos a ser profesoras de Lengua Portuguesa, entonces, el Español entra como una obligatoriedad en la carrera. (Clara, PEFEFG1)

(14) Yo no elegí ser profesora de Español, lo que me atrajo en el carrera fue la literatura. (...) No sabía que iba a tener que salir licenciada también en español [Entrevistador.: ¿En qué momento tomaste conciencia de ello?]. Nada más empezar la carrera. ¡Me llevé un susto!, porque pensé que [el español] era sólo una disciplina del Vestibular (...) Me vi teniendo que estudiar español aquí para enseñarlo después. Y mi experiencia no ha sido buena. (...) Al principio bien (...), estábamos todos entusiasmados, ¿sabes? Pero, a lo largo de la carrera fue predominando la frustración. Sólo les siguió gustando el español a los que ya tenían contacto antes y vinieron con la intención de mejorarlo. (Genoveva, PEF-EFG2) (Genoveva, PEF-EFG2)

(Andrade Neta, 2011, p. 264)

(15) ¡Adoro [las clases de ELE]! El día que más me gusta venir a la facultad es cuando tengo clase de lengua extranjera, porque es la asignatura que quiero enseñar (...) (Beatriz, PEF- EFG1) (Andrade Neta, 2011, p. 268)

(16) Me siento mal en la carrera de Letras, no me encuentro a gusto [...], porque por más que yo prepare las clases con dedicación, no siento el feedback del grupo. No es una cuestión de que les guste o no les guste el español, eso no me preocupa. El problema es que ellos vienen con un estereotipo de la lengua y sólo quieren el portugués y ellos no ven la oportunidad de estar estudiando una lengua extranjera que podría, incluso, contrastarse con la lengua materna [...] (P1, PEFP-EFG1) (Andrade Neta, 2011, p. 272)

Esas declaraciones que acabamos de ver ponen de relieve muchos temas que necesitamos discutir cuando hablemos de la calidad de la formación inicial de profesores de ELE en Brasil. Sin ahondar en el debate, que se escapa del objetivo de este artículo, queremos tan solo señalar algunos aspectos que inciden, de forma negativa, en la formación inicial en el área de Letras: (a) las carreras de doble 
habilitación y la formación del profesor de Español por defecto, o sea, aquel que al elegir Letras, opta automáticamente por la formación en ELE de forma obligatoria; (b) la ignorancia de los noveles acerca de la finalidad de las especificidades de formación de una licenciatura en Letras, que se vuelve más aguda cuando solo se toma conciencia de ello al final de la carrera; (c) la dicotomía teoría-práctica y la discrepancia entre la finalidad de la carrera y la formación que se ofrece en la misma como factores que agravan la inconsciencia o ignorancia citada en el ítem anterior; (d) el malestar de los profesores formadores al sentir la falta de retroalimentación de sus alumnos en el aula, que se manifiesta bajo la forma de desinterés e indiferencia hacia las clases de ELE.

Ya sabemos que, en Brasil, la formación inicial de calidad en las carreras de Letras con doble habilitación no es una tarea fácil, debido no solo a las limitaciones de tiempo, sino también a las condiciones previas de formación lingüística de los admitidos. Estamos plenamente de acuerdo con la investigadora de la Universidad de São Paulo (USP) y co-autora de las OCEM (Brasil, 2006), Neide González (2004, p. 1), cuando dice, en tono de desahogo, que:

Los profesores de las carreras de Letras hacemos un verdadero milagro para formar, generalmente (en la mejor de las hipótesis) en cuatro años [que pueden ser menos o más de 4], un hablante, investigador y profesor de lenguas en general desconocidas o poco conocidas cuando el estudiante llega a la universidad.

Al averiguar cuáles fueron las motivaciones de los entrevistados para la elección del Español como segunda habilitación, encontramos cinco categorías de respuestas, conforme se puede apreciar más adelante, en el gráfico 2: a) el 37\% eligió la lengua por la facilidad para aprobar los exámenes de selectividad; b) el 32\% optó por el español, porque ya les gustaba la lengua a partir de las experiencias previas a su ingreso en la universidad (gustatividad); c) el 12\% hizo esa elección por interés en profesionalizarse en el área, pues ya enseñaban esta lengua; el 3\% presentó otras motivaciones diferentes como, por ejemplo, trabajar como traductor de textos; y, finalmente, el 16\% no informó sus motivaciones, o bien por falta de claridad en las contestaciones o bien por ausencia de respuesta a la pregunta correspondiente. 


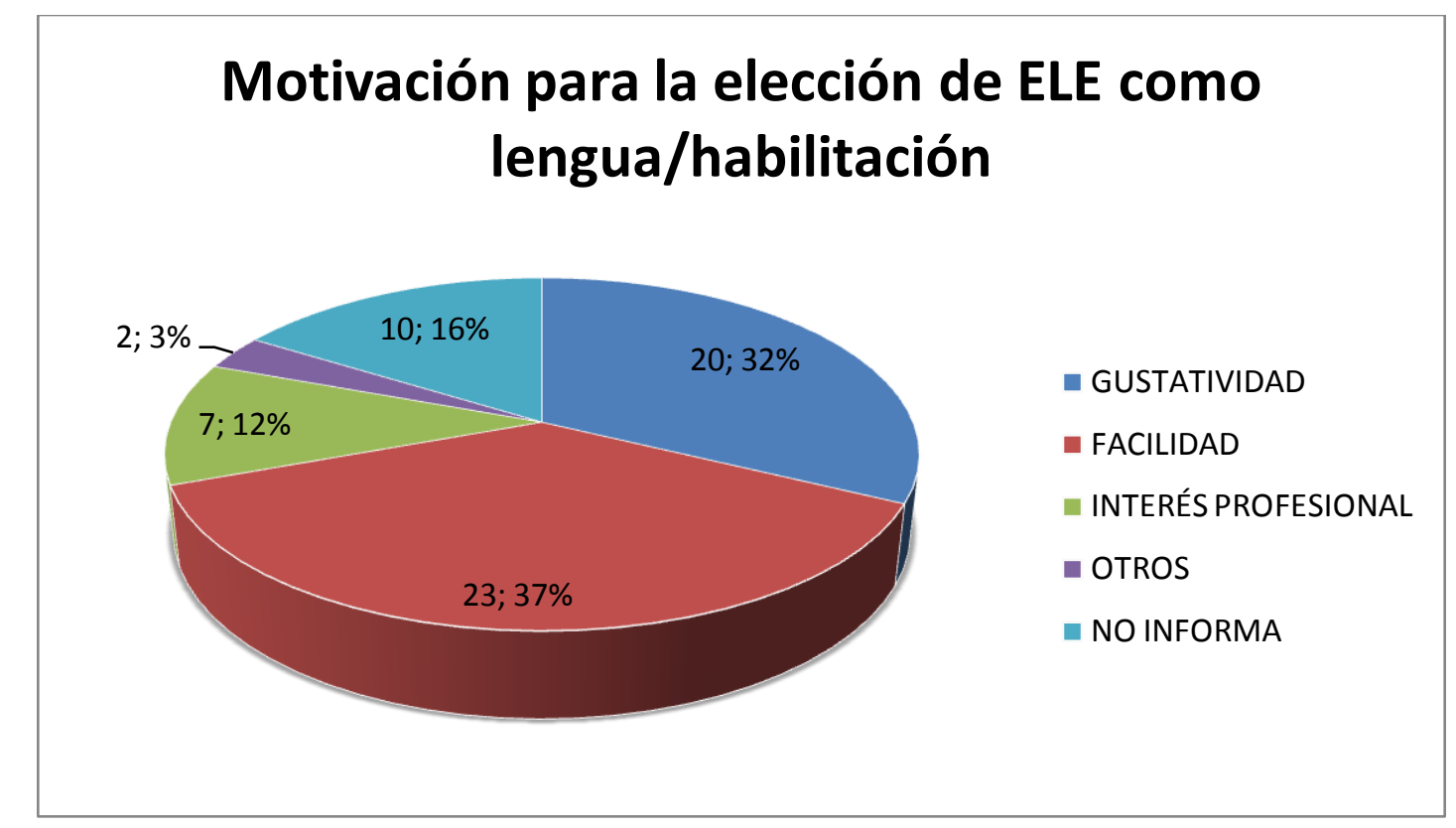

Gráfico 2: Motivación para la elección de ELE como lengua/habilitación de los PEF y PEE

(Andrade Neta, 2011, p. 276)

Aunque podríamos detenernos en otros aspectos relacionados con la motivación de los entrevistados para elegir ELE como lengua/habilitación, vamos a concluir este artículo centrándonos en la relación entre la facilidad y la gustatividad, conforme hemos prometido en la introducción del texto.

Como ya hemos adelantado, la gustatividad es un fenómeno afectivo que ha emergido de los datos de nuestro estudio. Aunque es frecuente encontrar, en otras investigaciones, referencias a lo que hemos denominado gustatividad, podemos constatar en las revisiones de literatura en el área, que ese componente de la afectividad humana aún no ha sido investigado como merecería, teniendo en cuenta su relevancia afectiva en las interrelaciones educativas. Silva (2002), por ejemplo, recoge declaraciones que tratan de la misma temática que las nuestras y considera el fenómeno manifestado en ellas como un componente de la influencia emocio-social; en Cunha (2010), la gustatividad emerge como una cualidad auto-percibida por los buenos profesores universitarios; y en Jesús (2007), aparece relacionada con el bienestar docente, como una actitud docente, cuya ausencia puede influir en la motivación del alumno.

En nuestra investigación, ese fenómeno tan corriente y frecuente en declaraciones de discentes y docentes acerca de su relación con la escuela, la profesión, las materias curriculares, etc. aparece con el estatus de emoción. Nuestra contribución al 
estudio de ese fenómeno ha sido triple: primero, le atribuimos un término llamativo y original para darle visibilidad; segundo, le atribuimos un estatus en cuanto fenómeno afectivo, buscando comprenderlo desde la perspectiva teórica (como una clase de reacción emocional, al amparo de la teoría damasiana) y metodológica (como un concepto concreto, con base en Taylor \& Bogdan, 1987); tercero, sugerimos una definición para la gustatividad en base a los datos empíricos y al marco teóricometodológico adoptado en nuestro estudio. Así, entendemos la gustatividad como:

\begin{abstract}
Una reacción emocional no deliberada, de origen inconsciente, que se conforma a través del aprendizaje durante el desarrollo individual y se manifiesta automáticamente con relación a personas, grupos, objetos, actividades, lugares y situaciones cotidianas. Ese tipo de emoción, comparte con las emociones reconocidas como tales, las siguientes características: transmite una señal, es fruto de una evaluación automática, se desencadena de forma ajena a la conciencia, tiene valencia, pone al organismo en un estado de estar listo para la acción, cambia en función de un cambio en las circunstancias desencadenantes, influye en el procesamiento cognitivo $\mathrm{y}$, probablemente, se acompaña de sensaciones somáticas, aunque sean muy leves. (Andrade Neta, 2011, p. 287)
\end{abstract}

El término "gustatividad" es una traducción que hemos sugerido del neologismo "gostatividade" (en portugués), acuñado por Solineide Maria de Oliveira, una profesora en formación, participante de nuestra investigación, que nos autorizó a adoptar el término, incluirlo en un marco teórico-metodológico que le diera visibilidad y a divulgar su nombre como autora del mismo, lo que hacemos con gratitud y alegría.

En fin, la gustatividad es un fenómeno afectivo de gran relevancia en la docencia, ya sea como aprendices de ELE, ya sea como profesores en formación o como profesores formadores. Su presencia ejerce una influencia positiva en la relación cíclica: profesor-enseñanza-alumno-aprendizaje-lengua y su ausencia o negación, interfiere en las relaciones intra e interpersonales que se establecen entre los pares del proceso de enseñanza-aprendizaje de ELE. Según la percepción de los participantes:

(17) Si no te gusta lo que aprendes, lo que está siendo transmitido, lo que manejas en tu cotidiano, tu vivencia en el aula no tendrá resultado, tanto en lo que respecta al profesor para contigo, como de ti para con el profesor. [... Es muy importante que te guste, que lo ames, que te guste, que te interese lo que estás haciendo [...] Si no me gusta mucho lo que estoy haciendo, eso lo va a dificultarlo todavía más. (Sofía, PEF-EI)

(18) Cuando haces algo que te gusta, te dedicas a ello y haces todo para aprenderlo. (Irene, PEF-EI)

(19) En este semestre estoy sintiéndome desmotivada porque estoy estudiando algunos temas que no me resultan muy agradables y cuando a uno no le gusta algo, es más difícil querer aprenderlo [...] (Raquel, PEF-EI) 
(20) Cuando el profesor está haciendo lo que le gusta, él consigue llamar nuestra atención. (Loli, PEF-EFG2)

(Andrade Neta, 2011, p. 245)

Hechas esas aclaraciones sobre la gustatividad, pasemos a su relación con la facilidad. Decíamos antes que una segunda creencia, muy presente en el escenario investigado, tiene que ver con la facilidad como factor de motivación para la elección de ELE como segunda habilitación en Letras. Hemos dicho también que esa elección se hace antes del ingreso en la carrera, cuando se elige la lengua extranjera de la que se quiere examinar. Una vez que se ingresa en la universidad, la lengua del examen pasa a ser automáticamente la segunda habilitación. A esa creencia subyace la idea de que la facilidad del español como factor de motivación está reñida con la gustatividad por la lengua. He aquí el punto de fragilidad de esa creencia. En el gráfico 2, hemos podido observar que el $37 \%$ de los entrevistados eligió el español por la facilidad, frente al $32 \%$ de los que lo eligieron por la gustatividad y al $12 \%$ que lo hizo por el interés de profesionalizarse en esta área. Pues bien, si consideramos que este último grupo eligió la habilitación porque ya actuaba en el área y ya les gustaba la lengua antes de su ingreso, y le sumamos el $32 \%$ de los de la gustatividad, concluiremos que el $44 \%$ de los aspirantes a Letras ya ingresó en la carrera con el "canal de la gustatividad" abierto. O sea, para el grupo de sujetos investigados, la facilidad no es el principal factor motivacional para la elección del ELE, sino la gustatividad. Los datos se vuelven aún más interesantes, si ahondamos un poco más y desvelamos la gustatividad que la facilidad esconde.

Un poco más del 50\% de los participantes que estamos tomando como referencia para este análisis, PEF y PEE, afirmó haber estudiado ELE antes de someterse al examen de selectividad. La mayoría empezó su andadura en el aprendizaje del español en los llamados "cursinhos pre-vestibulares"; otros, habían hecho cursos de corta duración, algunos ofrecidos por la propia institución-locus; algunos más habían estudiado en academias de idiomas y, un número muy reducido dio ELE en el último año de escolarización, en la enseñanza media. Y ha sido en estos primeros contactos en los que emergió la gustatatividad por la lengua. Veámoslo:

(21) Fui invitado para hacer un curso de Español, muy rápido, de tan sólo un mes. [...] $Y$ a partir de ese primer contacto con el español, me apasioné por la lengua. [...] Después de este curso me pasó a gustar la lengua, aprendí a comunicarme a través 
de ella, y eso me interesó bastante, incluso para querer enseñarla. (Juan, PEF-EI) (Andrade Neta, 2011, p. 277)

(22) He querido mucho intentar el Vestibular para Español, porque tuve la primera experiencia con el español en un "cursinho", me gustó mucho la facilidad del idioma, mucho más que el inglés, me gustó mucho, en un primer momento por eso [...] Hoy en día, cada cosa que aprendo [en español] es para mí una victoria, debido a todas las dificultades a las que ya me enfrenté con la lengua inglesa [...] (Sofía, PEF-EI) (Andrade Neta, 2011, p. 285)

No queda duda de que las semejanzas español-portugués en combinación con el entrenamiento específico que los "cursinhos" ofrecen, ha dado lugar a una fórmula exitosa para los participantes de esta investigación que eligieron el español, tomando como criterio la facilidad, como opina Angelina

(23) Pasé a estudiar español en un curso "pre-vestibular" y decidí optar por esta lengua en el Vestibular. Creamos un pre-concepto de que es más fácil y hasta cierto punto lo es. Me ha parecido más fácil, al menos en el Vestibular, en la interpretación de texto [...] De hecho, no me ha ido mal el examen, no, pero aquí en la universidad la cosa se complicó un poco. (Angelina, PEF-EI)(Andrade Neta, 2011, p. 279-280)

La decisión de Angelina, al igual que la de otros entrevistados, ha sido sumamente inteligente, tanto desde el punto de vista cognitivo como emocional, ya que ha representado una elección ventajosa para la conquista de sus metas personales que, en aquella ocasión, iban dirigidas a aprobar la selectividad.

Es muy habitual que los profesores de ELE nos empeñemos en combatir el "imaginario del facilismo" (Celada, 1992, p. 31) por temor a sus efectos negativos a la larga. Farías Fernández (1997, p. 71) advierte que "si tales proximidades parecen, de entrada, altamente rentables a la consecución de nuestra tarea, sus efectos negativos, en cambio, se multiplican en el aula [...]". Sin embargo, creemos que el centrarnos tanto en los efectos negativos de la facilidad ofusca nuestra visión y nos impide ver que la facilidad también tiene una cara positiva, ya que puede funcionar como un desencadenante de la gustatividad por esa lengua. Esta vinculación afectiva se vuelve más expresiva y se hace notar, especialmente cuando los aprendices comparan su experiencia con la lengua inglesa, que han estudiado durante casi una década de escolarización, pero nunca efectivamente haberla aprendido.

(24) Hice español porque siempre he estudiado inglés en la enseñanza media, nunca me gustó, nunca aprendí inglés. (Juana, PEE-EI) 
(25) Mi contacto con la lengua española fue después de la enseñanza media, en el "prevestibular". Opté por español creo que por una cuestión de comprensión [de texto, de los contenidos...], porque estudié inglés desde el $5^{\circ}$ año de la enseñanza fundamental y nadie comprende nada [lo dice utilizándose de pausas para enfatizar la frase], es un engaño. Entonces elegí español por la comprensión, no porque fueran lenguas [español y portugués] totalmente parecidas [...] (Esteban, PEF-EFG3)

(26) Tuve clase de inglés en la Educación Básica, pero ni lo tengo en cuenta porque no vale para nada. (Itziar, PEF-EI)

(Andrade Neta, 2011, pp. 279-281)

El fracaso de la enseñanza de la lengua inglesa en las escuelas públicas brasileñas es un problema complejo, ampliamente identificado y reconocido, que aún está pendiente de solucionarse mediante una seria y eficaz inversión en diferentes frentes. Mientras eso no ocurre, estamos negando a una parcela significativa de la sociedad un derecho legalmente constituido, aumentando lo que Paiva (2003) llama de foso entre la educación de las élites y la de las clases populares.

Además del impacto social, no podemos negar las pérdidas de naturaleza afectiva. Los sucesivos fracasos de la enseñanza del inglés refuerzan la creencia de que esta lengua o es muy difícil de aprender o, efectivamente, no se aprende.

(27) Siempre he querido aprender una lengua extranjera, siempre he tenido ganas de aprender, primero el inglés, porque en la escuela, hasta hace poco, sólo teníamos inglés. Entonces, yo tenía ganas de aprender inglés, escuchaba canciones. Cuando hice el "pre-vestibular", pensé así: ¡Ah! esta [refiriéndose a la lengua española] es más fácil, esta es la que voy a conseguir aprender y la que voy a conseguir enseñar. Vaya pretensión la mía, ¿verdad? [Entrevistadora: Por qué lo dices, ¿acaso te considerabas incapaz de aprender una lengua extranjera?] Me consideraba incapaz de aprender la lengua extranjera inglés, y hasta el día de hoy [risa], me veo hasta hoy con esta incapacidad. (Nuria, PEE-EFG2)

(28) Siempre he tenido dificultades con el inglés, que sólo enseñaban el verbo "To Be" y aun así no lo aprendíamos [...] (Angelina, PEF-EI)

(29) [Otro motivo por el que opté por el español fue] por el inglés haber sido frustrante en mi vida, siempre lo estudié, pero nunca lo aprendí. (Alejandro, PEE-EFG2)

(Andrade Neta, 2011, p. 282)

La Teoría de la Atribución de Causalidad, desarrollada inicialmente por Weiner (1977, 1988), tiene mucho que decirnos sobre las causas, comportamientos y sentimientos de los alumnos frente a las situaciones de éxito o fracaso escolar. De acuerdo con ese marco teórico, la capacidad se percibe como una causa de fracaso estable e interna al sujeto. Cuando la participante Nuria (27), de la categoría profesora egresada, dice que "se sentía incapaz" de aprender inglés atribuye a sí misma su fracaso, o sea, a su incapacidad de aprender. Todo ello incidirá sobre la motivación, la autoestima, el autoconcepto y sobre la emocionalidad de la persona. 
Las repetidas experiencias de aprendizaje del inglés de buena parte de los participantes de nuestro estudio han sido marcadas por la ausencia de éxito en los resultados alcanzados al final de sus años de escolarización, lo que ha podido llevarles a sentirse incapaces de aprender esa lengua. Cuando se atribuye el fracaso a una causa estable, como es la capacidad, la repetición del fracaso merma las expectativas de futuros éxitos en esta empresa y fortalece las expectativas de que el fracaso se repita.

Para quienes han fracasado en el aprendizaje del inglés por sentirse incapaces de aprender una lengua extranjera, "el encuentro con la lengua española representa una segunda oportunidad" y al darse cuenta de que al salir de una clase, algo han aprendido les hace ver la lengua como "una lengua fácil, una lengua que ellos se sienten capaces de aprender" (Andrade Neta, 2011, p. 284). Veamos algunas de sus percepciones al respecto:

(30) Aunque digo que me siento incapaz de aprender inglés, reconozco que no me sentí incapaz de aprender español. (Nuria, PEE-EFG2)

(31) Di español en el "pre-vestibular", tuve mucha facilidad para aprenderlo, porque el inglés es aquello que te pasas toda la vida en el verbo To Be. Con el español pasó algo interesante, porque hice un año de "cursinho", pero durante todo el año asistí a las clases de inglés (...) Pero yo había optado por español y todavía no sabía nada. Entonces, unos dos o tres meses antes, empecé a asistir a las clases de Español. Tuve mucha facilidad, porque también la profesora era muy buena, ya me gustaba la lengua, me pasó a gustar todavía más. En esos tres meses aprendí muchas cosas y eso me animó. (Irene, PEF-EI) (Andrade Neta, 2011, pp. 284-285)

Si sumamos las tres categorías de motivaciones para la elección del ELE como lengua-habilitación (facilidad, gustatividad e interés de profesionalizarse), encontraremos que el $81 \%$ de los entrevistados que estamos analizando, optaron por el Español o bien por la gustatividad o bien por la facilidad. Si consideramos la relación entre resultados se vuelven más reflexionar sobre quién relación. En otras palabras, ¿les resulta fácil aprenderla (al

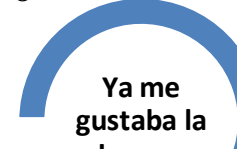
lengua gustatividad y facilidad, esos interesantes y nos llevan a antecede a quién en esta Tuve mucha gusta la lengua española porque les
facilidad menos en un principio) o les resulta más fácil aprenderla El ejemplo de Irene, el nos hace pensar que hay un gustatividad. En su declaración, antecedente de la percepción de

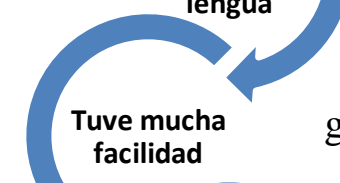
el Me pasó a gustar tndavía más Aprendí muchas cosas y eso me animó porque les gusta? último del bloque anterior (31), bucle entre facilidad y la gustatividad parece ser un la facilidad, pero esta última la 
incrementa: ya me gustaba la

lengua $\rightarrow$ tuve mucha facilidad $\rightarrow$ me pasó a gustar todavía más $\rightarrow$ aprendí muchas cosas y $\rightarrow$ eso me animó. Esta relación que estamos proponiendo se aprecia mejor en la figura 1 .

Cuando se trata del impacto de las experiencias cognitivas sobre la emocionalidad del aprendiz, no es fácil separar los componentes afectivos de los cognitivos. Para los participantes tampoco les ha resultado fácil desgranar esos elementos que, por su naturaleza, se interrelacionan en nuestra vida mental. Itziar logra una excelente descripción de esa confusa relación:

(32) Antes, debido a las dificultades que yo tenía en ELE, lo odiaba un poco, odiaba las clases, pensaba, ‘ ¡vaya! Hoy tengo clase de ELE', estaba siempre pendiente de los días y horarios de esta clase. Cuando tocaba, yo venía triste, y venía así, decaída y decía, ‘uuf, un día menos!' [...] No es que no me guste el español, pero es que tengo dificultad y uno acaba asociándolo al 'no gustarle' [...] Infelizmente, cuando al ser humano no se le da bien una cosa, tiende a criticarla, tiende a decir que la odia [ ...] Tuve clases de inglés en la educación básica, pero ni lo digo porque no vale la pena. (Itziar, PEF-EI) (Andrade Neta, 2011, pp. 285-286)

En algunas ocasiones, la autopercepción de las dificultades de aprendizaje puede obnubilar la relación de gustatividad hacia el objeto de aprendizaje, en nuestro caso el ELE. Cuando el alumno siente dificultad para aprender, la interpreta como una señal de incapacidad cognitiva. La declaración de Itziar nos sugiere la instalación de un conflicto entre el deseo de acercarse al objeto porque le gusta y, a la vez, apartarse, porque le resulta difícil asimilarlo.

Encontraremos una explicación interesante para ese fenómeno en las clásicas investigaciones de Kurt Lewin (1973), sobre las situaciones conflictuales del tipo acercamiento-alejamiento. En sus experimentos con niños, constató que cuando se interpone una barrera que dificulta la consecución de determinado objetivo (en nuestro caso, aprender ELE), cuyos intentos de superación redundan en daño personal (como el sentirse incapaz de aprender) o en fracaso, la barrera (en este caso, la dificultad de aprendizaje) adquiere una valencia negativa y la intensidad de ese vector negativo tiende a incrementarse, pudiendo llegar a ser más intenso que el positivo (la gustatividad, el deseo de aprender la lengua, etc.). Ante situaciones conflictuales de este tipo, Lewin observó que los sujetos tienden a abandonar "el campo", es decir, desisten de seguir intentando conquistar su objetivo. Eso fue lo que le pasó a Victoria, una de las 
participantes de nuestra investigación, cuando percibió que tenía dificultad para aprender español, a pesar de haber ingresado en la carrera motivada por el ELE:

(33) A algunos de mis compañeros, a pesar de las dificultades de aprendizaje, les gusta el español e intentan aprenderlo. Yo no, cuando veo que algo no se me da bien, lo dejo [...], voy a buscar otro camino. (Victoria, PEF-EI) (Andrade Neta, 2011, p. 298)

La dificultad de aprendizaje del ELE autopercibida por Victoria la llevó a abandonar "el campo" y a dirigir sus esfuerzos hacia otro interés. Y fue así como se enamoró del área de Literatura. Pero, en casos como este, el problema no se restringe a la esfera de las decisiones personales con sus respectivas consecuencias. El abandono de campo que se produce solo es parcial, de naturaleza intrapersonal, puesto que para graduarse, los alumnos que se encuentran en las mismas circunstancias que Victoria tendrán que aprobar también las asignaturas referentes a la habilitación de ELE. Ante la imposibilidad institucionalmente establecida de abandono total del campo y ante la falta de disposición para superar sus dificultades, esos alumnos optarán por hacer lo que hizo Clara (véase el siguiente ejemplo, el 34), "ir tirando", estudiando para aprobar las asignaturas, pero sin implicarse integralmente en el proceso de formación como profesores de ELE. Más adelante, ante las oportunidades de trabajo en esta área, acabarán asumiendo el compromiso de enseñar lo que no han logrado aprender porque abandonaron el campo cognitiva y afectivamente. Sin lugar a dudas, la gustatividad habrá sufrido solución de continuidad, hasta que vuelva a despertarse.

\section{CONSIDERACIONES FINALES}

Aunque necesitamos ahondar más en la comprensión de la relación entre la facilidad y la gustatividad, el análisis del corpus de nuestra investigación nos lleva a postular que esos dos fenómenos se interrelacionan, siendo que la percepción inicial de la facilidad de la lengua española funciona como un Estímulo Emocionalmente Competente (EEC), o sea, un desencadenante de la gustatividad. La explicación para ello estribaría en el hecho de que el acercamiento a la lengua española como una lengua "fácil de aprender", les ayudaría a rescatar la auto-confianza, a elevar la auto-estima y a devolverles la autopercepción de capacidad para aprender una lengua extranjera. Esa impresión positiva inicial puede afianzarse (como le pasó a Nuria que se convirtió en 
profesora de ELE -véanse los ejemplos 7, 27 y 30) o sufrir solución de continuidad, como le ha pasado a Clara, en quien nos inspiramos para el título de este artículo:

(34) ¡El español era tan fácil y ahora se ha vuelto tan difícil! Pero, ¡qué se le va a hacer! Si ya estás en el barco, vas tirando... y yo fui tirando hasta el octavo semestre, y aquí estoy, siendo formada como profesora de ELE sin querer haber entrado en la carrera para estudiar español. [...] Soy una persona a la que realmente no le gusta el español. (Clara, PEF-EFG1) (Andrade Neta, 2011, p. 268)

Ante los efectos negativos de la proximidad del español y del portugués, sobre la que se funda la creencia de la facilidad para aprender ELE, Farías Fernández (1997, p. 72) defiende que los profesores de ELE tenemos dos desafíos en nuestra labor docente: el primero consiste en poner en marcha, junto a los aprendices, "un proceso de concienciación de la diversidad del español a través del descubrimiento conjunto de sus dificultades" y, en segundo lugar, "concretarlo en prácticas pedagógicas contrastivas especiales que, tomando en cuenta la fricción entre sendos sistemas lingüísticos, ofrezcan un cauce efectivo de aprendizaje".

Sin entrar en desacuerdo con estas dos orientaciones, quisiéramos advertir del cuidado que debemos tener al intentar combatir la creencia en la facilidad -la misma que condujo a los alumnos a elegir ELE como lengua-habilitación-, porque podemos destruir, asimismo, la autoconfianza en la capacidad de aprender esa lengua y la gustatividad desencadenada por la facilidad.

El hecho de que, en sí mismas, las lenguas no sean fáciles o difíciles de aprender, llevará a que, inevitablemente, los profesores en formación se den cuenta de las especificidades y complejidades del español como lengua extranjera y evalúen en qué grado les resulta fácil o difícil aprender esa lengua para que puedan calibrar la medida del esfuerzo que han de emprender para alcanzar sus objetivos.

Para la mayoría de los sujetos de nuestra investigación, aprender español es fácil porque se sienten capaces de aprenderlo y eso fomenta el acercamiento a la experiencia de aprendizaje y desencadena o refuerza la gustatividad por esa lengua. Consideramos ser esta una "cara" positiva de la facilidad que tantas veces sentenciamos a muerte en el aula de ELE. Pero, en el sentido contrario, la percepción de dificultades para aprender ELE puede incidir sobre la gustatividad, enmascarándola. Solo una intervención emocional y racional a la vez podría ayudar al aprendiz a rescatar la gustatividad por la lengua, ante las dificultades de aprendizaje. 
Con este trabajo, esperamos haber podido contribuir con las discusiones acerca de la formación del profesorado de ELE en Brasil. Y para mantener la invitación a que continuemos reflexionando sobre el papel de la facilidad del español y su relación con la gustatividad, concluimos este artículo citando una reflexión que registramos en el texto en el que nos basamos para esta producción:

\begin{abstract}
Cuando nos dejamos llevar por nuestras creencias de que '[...] el $80 \%$ de los que están aquí [en Letras-UESC], están porque el español es fácil o porque es fácil aprobar' (Maricarmen, PEF-EI), podemos llevar a cabo prácticas que, con la intención de ponerles en contacto con la realidad de la no facilidad, les resulten aversivas y contraproducentes. $\mathrm{Si}$, al contrario, contribuimos a que la gustatividad se consolide, la deconstrucción de la creencia de la facilidad ocurrirá de forma paulatina y con la suavidad necesaria para no convertirse en un factor negativo e impeditivo del éxito académico en la formación de profesores de ELE. (Andrade Neta, 2011, p. 286)
\end{abstract}

Esa toma de conciencia es un paso hacia la educación emocional del profesorado de ELE que, a la larga, repercutirá sobre su metodología de enseñanza, su actitud ante el error en el aula y el miedo a cometerlo y, lo más importante, sobre las interrelaciones entre los pares del proceso de enseñanza-aprendizaje.

\title{
REFERÊNCIAS
}

Andrade Neta, N. F. (2000). Aprender español es fácil porque hablo portugués: ventajas $\mathrm{y}$ desventajas de los brasileños para aprender español. Cuadernos Cervantes de la Lengua Española, 29, 46-55.

Andrade Neta, N. F. (2011). Emociones y sentimientos en la formación de profesores de Español como Lengua Extranjera. 484 p. Tesis doctoral inédita, Universidad Complutense de Madrid, Madrid.

Bechara, A. (2003). O papel positivo da emoção na cognição. In V. A. Arantes (Org.), Afetividade na escola: alternativas teóricas e práticas. São Paulo: Summus.

Brasil. Ministério da educação. Secretaria de Educação Básica (2006). Orientações Curriculares para o Ensino Médio. Linguagens, códigos e suas tecnologias. Conhecimentos de Espanhol. Brasília: Autor.

Celada, M. T. (1992). Pasando en limpio algunas cuestiones. APEESP, 4, 25-38.

Damasio, A. (2007). El error de Descartes. Barcelona: Crítica.

Farías Fernández, M. (1997). La enseñanza del español en Brasil: un reto político y cultural. In F. Moreno, M. Gil, \& K. Alonso (Ed.). Actas del Congreso Internacional de 
ASELE. La enseñanza del Español como Lengua Extranjera: del pasado al futuro, Alcalá de Henares, Madrid, ES, 8. Recuperado el 16 febrero 2013, de http://cvc.cervantes.es/ensenanza/biblioteca_ele/asele/pdf/08/08_0001.pdf

González, N. M. (2004, marzo). Lugares de reflexión en la formación del profesor de E/LE (la particular situación de Brasil). Revista RedEle, 0. Recuperado el 26 de noviembre de 2010, de http://educacion.es/redele/revista/neide_gonzalez.shtml

Guerra, I. C. (2008). Pesquisa qualitativa e análise de conteúdo: sentidos e formas de uso. Cascais, Portugal: Principia.

Lewin, K. (1973). Dinámica de la personalidad. Madrid: Morata.

Nascimento, D. M. (2002). Metodologia do trabalho científico. Rio de Janeiro: Forense.

Paiva, V. L. M. O. (2003). A LDB e a legislação vigente sobre o ensino e a formação de professor de língua inglesa. In C. M. T. Stevens, \& M. J. Cunha, Caminhos e Colheitas: ensino e pesquisa na área de inglês no Brasil (pp. 53-84). Brasília: UnB.

Sabariego, M. \& Bisquerra, R. (2004). Fundamentos metodológicos de la investigación educativa. En R. Bisquerra (Coord.), Metodología de la investigación educativa (pp. 1949). Madrid: La Muralla.

Taylor, S. J., \& Bogdan, R (1987). Introducción a los métodos cualitativos de investigación. Barcelona: Paidós.

\section{A AUTORA}

Nair Floresta Andrade Neta é professora assistente de Espanhol na Universidade Estadual de Santa Cruz (UESC).

E-mail: nairandrade@ hotmail.com 